To be presented at Microscopy \& Microanalysis 98

Atlanta, Georgia, July 12-16, 1998, and published in Proceedings

\title{
The Atomic-Scale Origins of Grain Boundary Superconducting Properties
}

S. J. Pennycook, ${ }^{1}$ J. Buban, ${ }^{2}$ C. Prouteau, ${ }^{1,2}$ M. F. Chisholm ${ }^{1}$

P. D. Nellist ${ }^{3}$ and N. D. Browning ${ }^{2}$

${ }^{1}$ Solid State Division, Oak Ridge National Laboratory

P.O. Box 2008, Oak Ridge, Tennessee 37831-6030

2Department of Physics, University of Illinois at Chicago

Chicago, Illinois 60607-7059

${ }^{3}$ Cavendish Laboratory, Cambridge University

Madingley Road, Cambridge CB3 OHE, UK

"The submitted manuscript has been authored
by a contractor of the U.S. Government under
contract No. DE-AC05-960R 22464 .
Accordingly, the U.S. Government retains a
nonexclusive, royalty-free license to publish or
reproduce the published form of this
contribution, or allow others to do so, for U.S.
Government purposes."
RECEIVED

JUN 101998

O.STI

\author{
prepared by \\ SOLID STATE DIVISION \\ OAK RIDGE NATIONAL LABORATORY \\ Managed by \\ LOCKHEED MARTIN ENERGY RESEARCH CORP. \\ under \\ Contract No. DE-AC05-96OR22464 \\ with the \\ U.S. DEPARTMENT OF ENERGY \\ Oak Ridge, Tennessee
}

February 1998 


\section{DISCLAIMER}

This report was prepared as an account of work sponsored by an agency of the United States Government. Neither the United States Government nor any agency thereof, nor any of their employees, makes any warranty, express or implied, or assumes any legal liability or responsibility for the accuracy, completeness, or usefulness of any information, apparatus, product, or process disclosed, or represents that its use would not infringe privately owned rights. Reference herein to any specific commercial product, process, or service by trade name, trademark, manufacturer, or otherwise does not necessarily constitute or imply its endorsement, recommendation, or favoring by the United States Government or any agency thereof. The views and opinions of authors expressed herein do not necessarily state or reflect those of the United States Government or any agency thereof. 


\title{
THE ATOMIC-SCALE ORIGINS OF GRAIN BOUNDARY SUPERCONDUCTING PROPERTIES
}

\author{
S. J. Pennycook*, J. Buban ${ }^{\ddagger}$, C. Prouteau* ${ }^{\ddagger}$, M. F. Chisholm*, P. D. Nellist ${ }^{\ddagger \ddagger}$, and N. D. Browning \\ * Solid State Division, Oak Ridge National Laboratory, P.O. Box 2008, Oak Ridge, TN 37831-6030 \\ $\ddagger$ Dept. Physics (M/C 273), University of Illinois at Chicago, Chicago, IL 60607 \\ $\ddagger \ddagger$ Cavendish Laboratory, Madingley Road, Cambridge, CB3 OHE,
}

Due to the extemely short coherence lengths of the high- $T_{c}$ superconductors (around $30 \AA$ in the $a-b$ plane), defects such as grain boundaries are obvious barriers to the flow of supercurrent. Within a few months of the discovery of these materials, it was shown how the critical current dropped four orders of magnitude as the grain boundary misorientaion increased from zero to $45^{\circ}$. Even today, there is no quantitative understanding of this behavior. A qualitative understanding is however possible through atomic resolution $Z$-contrast imaging on $\mathrm{YBa}_{2} \mathrm{Cu}_{3} \mathrm{O}_{7-\delta}$ and $\mathrm{SrTiO}_{3}$ bicrystal grain boundaries, combined with bond-valence-sum analysis².

The Z-contrast image of a $\mathrm{YBa}_{2} \mathrm{Cu}_{3} \mathrm{O}_{7-\delta}$ low angle grain boundary in Fig. 1 shows the same kind of reconstructed dislocation cores as seen in $\mathrm{SrTiO}_{3}$, containing reconstructions on both the $\mathrm{Cu}$ and $\mathrm{Y} / \mathrm{Ba}$ sublattices. In Fig. 2, an image of an asymmetric $30^{\circ}$ boundary in $\mathrm{YBa}_{2} \mathrm{Cu}_{3} \mathrm{O}_{7-\delta}$ shows the same units and unit sequence as expected for $\mathrm{SrTiO}_{3} . \mathrm{YBa}_{2} \mathrm{Cu}_{3} \mathrm{O}_{7-\delta}$ boundaries are wavy because of their non-equilibrium growth process, and therefore mostly asymmetric in nature, although small segments have the symmetric structure as shown in Fig. 3. It seems reasonable to assume that boundaries of other angles will also have similar structures in these two materials.

Atom column coordinates can be extracted from maximum entropy analysis, and bond-valence-sum analysis used to determine the $\mathrm{Cu}$ valence in each column. Fig. 4 plots the $\mathrm{Cu}(1)$ valence as a function of distance from the grain boundary plane. Although the numerical value in the highly distorted core region cannot be accurate, it is clear that the perturbation to the $\mathrm{Cu}$ valence is very significant, and the core region cannot be superconducting. A similar analysis for other angles reveals that the non-superconducting zone increases almost linearly with increasing misorientation angle, explaining the observed exponential drop in critical currents ${ }^{2}$. A similar analysis of a symmetric $36^{\circ}$ grain boundary shows a very different behavior (Fig 5). This boundary is constructed from the same cores as seen in Fig. 1, closely spaced and alternating between the two cation sublattices. The $\mathrm{Cu}$ valence through the $\mathrm{Cu}$-reconstructed core shows a strong valence drop, but this is not seen in the trace across the $\mathrm{Y} / \mathrm{Ba}$ core.

This would imply that symmetric boundaries have stronger links. The presence of symmetric portions in a predominantly asymmetric boundary (Fig. 3) are likely to be the origin of the strong-linked component deduced recently from transport measurements in magnetic fields ${ }^{3}$. A 2D schematic of the valence across the asymmetric boundary (Fig. 6) shows a continuous region of reduced valence, with a spectrum of boundary widths due to its quasiperiodic structure. Fig 7 suggests that only a portion of the symmetric boundary has reduced $\mathrm{Cu}$ valence.

\section{References}

1. D. Dimos, P. Chaudhari, J. Mannhart and F. K. LeGoues, Phys Rev Lett 61 (1988) 1653

2. N. D. Browning, J. P. Buban, P. D. Nellist, D. P. Norton, M. F. Chisholm, and S. J. Pennycook, Physica C, 295 (1998) Jan 20 issue

3. C. Prouteau et al, these proceedings

This research was sponsored by the Division of Materials Sciences, U.S. Department of Energy, under contract DE-AC05-96OR22464 with Lockheed Martin Energy Research Corp., by NSF under grant no. DMR-9503877, and by an appointment to the ORNL postdoctoral research program administered jointly by ORNL and ORISE. 

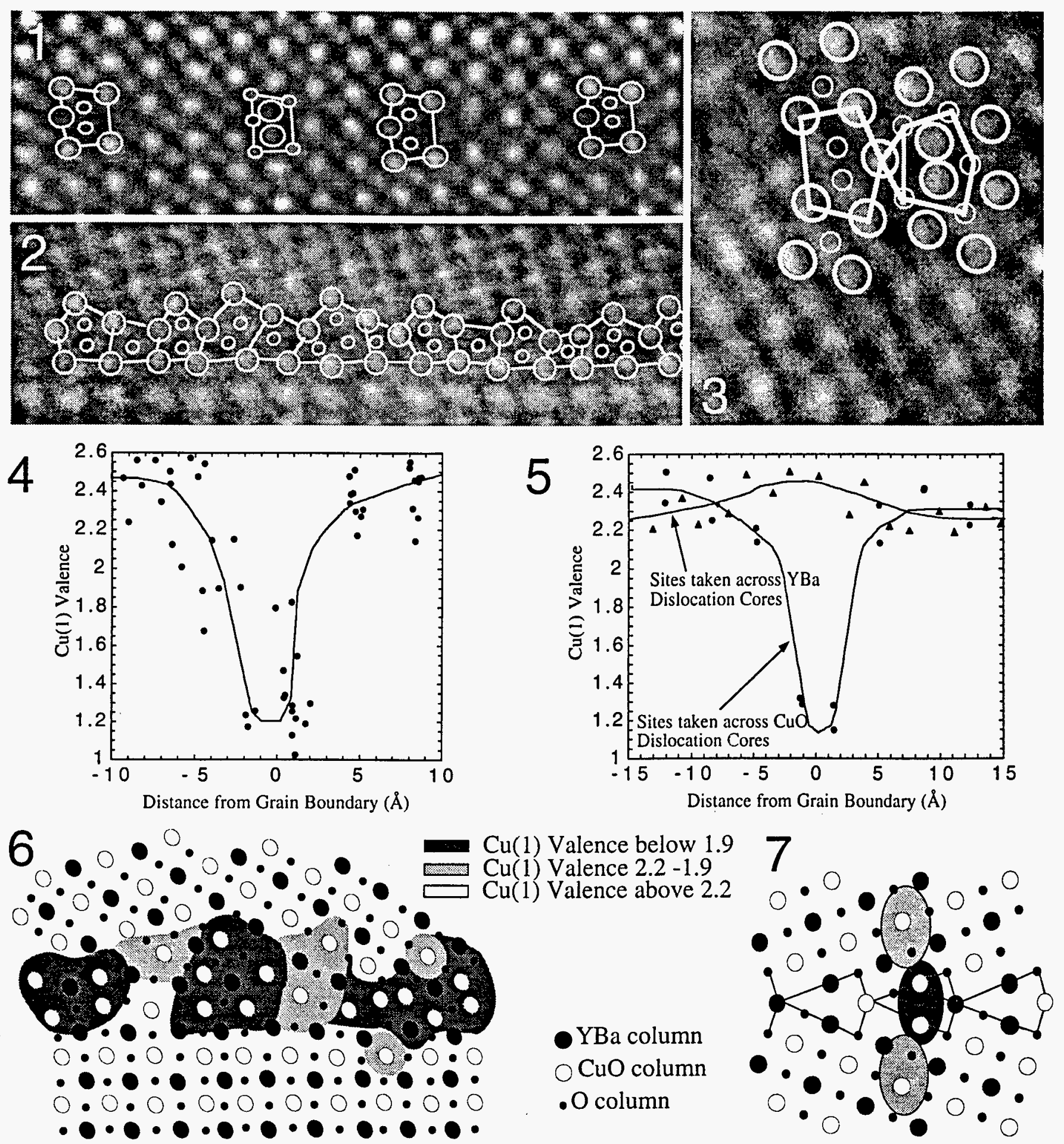

FIG. 1.--Z-contrast image of dislocation cores in a low angle $\mathrm{YBa}_{2} \mathrm{Cu}_{3} \mathrm{O}_{7-\delta} \delta$ grain boundary. Large circles represent $\mathrm{Y} / \mathrm{Ba}$ columns, small circles $\mathrm{Cu}-\mathrm{O}$ columns.

FIG. 2.--Z-contrast image of dislocation cores in an asymmetric $30^{\circ} \mathrm{YBa}_{2} \mathrm{Cu}_{3} \mathrm{O}_{7} \delta$ grain boundary. FIG. 3.--Z-contrast image of a symmetric portion of the $30^{\circ} \mathrm{YBa}_{2} \mathrm{Cu}_{3} \mathrm{O}_{7-\delta} \mathrm{C}$ grain boundary.

FIG. 4.-- $\mathrm{Cu}(1)$ valence across the asymmetric $30^{\circ}$ boundary (Fig. 2) showing non-superconducting zone.

FIG. 5.-- $\mathrm{Cu}(1)$ valence across $\mathrm{Cu}$ and $\mathrm{Y} / \mathrm{Ba}$ cores in a symmetric $36^{\circ}$ boundary.

FIG. 6.--2D schematic of $\mathrm{Cu}(1)$ valence for the asymmetric $30^{\circ}$ boundary showing varying widths.

FIG. 7.--2D schematic of $\mathrm{Cu}(1)$ valence deduced for the symmetric $36^{\circ}$ boundary. 


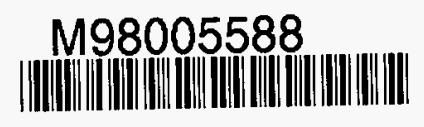

$\frac{\text { Report Number (14) ORNL/CP- }-96745}{\text { CONF- } 980713--}$

Publ. Date (11) $\frac{199802}{D O E / E R, X F}$
Sponsor Code (18)
UC Category (19) 